\title{
Autosomal recessive retinal dystrophy associated with two novel mutations in the RPE65 gene
}

\author{
Françoise $M$ arlhens ${ }^{1}$, Jean-M ichel Griffoin ${ }^{1}$, Corinne B areil ${ }^{2}$, Bernard A rnaud ${ }^{3}$,

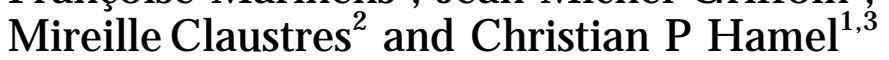 \\ ${ }^{1} \mathrm{~L}$ aboratoire de Neurobiologie de I'A udition, Plasticité Synaptique \\ ${ }^{2} \mathrm{~L}$ aboratoire de Biochimie $\mathrm{G}$ énétique, Institut de Biologie \\ ${ }^{3}$ Service d'O phtalmologie, $\mathrm{H}$ ôpital G ui de Chauliac, M ontpellier, France
}

\begin{abstract}
Retinal dystrophies are a complex set of hereditary diseases of the retina that result in the degeneration of photoreceptors. Recent studies have shown that mutations in RPE65, a gene that codes for a retinal pigment epithelium (RPE)specific protein thought to be involved in the 11-cis-retinoid metabolism, a key process in vision, cause severe, early onset retinal dystrophy. We describe two novel missense RPE65 mutations, L22P and H68Y, in a compound heterozygote with autosomal recessive retinal dystrophy. The relatively mild phenotype associated with these mutations suggests a possible link between the severity of the disease and the type of mutations in the RPE65 gene.
\end{abstract}

Keywords: RPE65; retinal pigment epithelium; photoreceptor; retinitis pigmentosa; retinal dystrophy; gene mutation

\section{Introduction}

Retinal dystrophies are hereditary disorders whose common feature is the degeneration of photoreceptors, rods and/or cones. Retinitis pigmentosa (RP) is the most frequent retinal dystrophy that affects 1 in 3 to 4000 individuals in developed countries. ${ }^{1,2} \mathrm{E}$ arly stages of typical R P are characterised by night blindness and loss of midperipheral visual field that reflect primary rod impairment. A s the disease progresses, patients lose far peripheral and central vision, eventually leading to blindness. Prominent clinical findings are the presence

Correspondence: Christian P Hamel, INSERM U. 254, Laboratoire de Neurobiologie de I'A udition-Plasticité Synaptique, 300, rue Auguste Broussonnet, 34295 M ontpellier cedex 5, France. Tel: (33) 4673369 75; Fax: (33) 4675256 01; E-mail: biomol@mnet.fr

Received 11 November 1997; revised 6 February 1998; accepted 18 February 1998 of bone spicule-shaped pigment in the retina and abnormal electroretinogram (ER G ) responses. In addition to typical RP, there are less frequent forms of retinal dystrophy which appear to involve either primarily cones or equally rods and cones. ${ }^{3,4}$ Clinical varieties of retinal dyctrophy are most frequently nonsyndromic and can be inherited as autosomal dominant, autosomal recessive, $\mathrm{X}$-linked or digenic diseases, with extensive allelic and nonallelic heterogeneity. ${ }^{5,6}$

The retinal pigment epithelium (R PE) is a single celllayered tissue in close contact with the photoreceptor outer segments which performs many functions important for the physiology of photoreceptors. A mong them, the periodic phagocytosis of the outer segment tips, ${ }^{7}$ a process whose defect leads to retinal degeneration, ${ }^{8}$ and the metabolism of 11-cis-retinoids ${ }^{9}$ are key processes to vision. R PE 65 is a $65-\mathrm{kD}$ a protein specific to the $\mathrm{RPE} .{ }^{10}$ W hile the precise role of $\mathrm{R} P E 65$ remains 
unclear, its involvement in retinoid metabolism seems certain $^{11}$ and implies a functional relationship with photoreceptor physiology. It was recently found that mutations in RPE 65 cause childhood onset of severe retinal dystrophy. ${ }^{12,13}$ In an effort to further characterise mutations in this gene, we screened 184 unrelated patients with various types of retinal dystrophies. We report here two novel missense mutations in a compound heterozygote with autosomal recessive retinal dystrophy.

\section{Materials and Methods}

\section{Single-strand Conformation Analysis (SSCA)}

Unlabelled SSCA Each of the 14 exons of the RPE 65 gene was amplified by combining 20 pmoles of forward and reverse intronic primers, ${ }^{12} 200 \mathrm{ng}$ of genomic DNA, $1 \mathrm{U}$ of Taq DNA polymerase (E urogentec, Belgium) in a $50 \mu \mathrm{l}$ volume containing $75 \mathrm{mM}$ Tris- $\mathrm{HCl}$ pH 9.0, $20 \mathrm{mM}$ $\left(\mathrm{NH}_{4}\right)_{2} \mathrm{SO}_{4}, 2.0 \mathrm{mM} \mathrm{M} \mathrm{gCl} 2,20 \mu \mathrm{M}$ of each dNTP and $0.01 \%$ Tween 20 . Following a denaturation step $\left(94^{\circ} \mathrm{C}\right.$ for $\left.5 \mathrm{~min}\right)$ amplification was carried out for 35 (exons $3,11,12$ ) or 40 (exons $1,2,4-10,13,14$ ) cycles at $94^{\circ} \mathrm{C}$ for $1 \mathrm{~min}, 56^{\circ} \mathrm{C}$ or $60^{\circ} \mathrm{C}$ for $1 \mathrm{~min}^{12}$ and $72^{\circ} \mathrm{C}$ for $2 \mathrm{~min}$. Twelve $\mu$ of PCR products were mixed with $4 \mu \mathrm{l}$ of stop solution (95\% formamide, $10 \mathrm{mM} \mathrm{NaOH}, 0.05 \%$ bromophenol blue, $0.05 \%$ xylene cyanol) and denatured for $2 \mathrm{~min}$ at $100^{\circ} \mathrm{C}$. Seven $\mu \mathrm{l}$ of each sample were then loaded on a Hydrolink MDE gel (FMC, USA ) and electrophoresed at room temperature in $0.6 \times$ TBE. G els were silver stained and air dried.

Labelled SSCA To study the familial segregation of the $L 22 P$ mutation, exon 2 of the RPE 65 gene was ${ }^{32} \mathrm{P}$-labelled and amplified by PCR as previously described. ${ }^{14}$ Five $\mu$ of labelled PCR products were mixed with $7 \mu$ l of stop solution ( $95 \%$ formamide, $10 \mathrm{mM} \mathrm{NaOH}, 0.05 \%$ bromophenol blue, $0.05 \%$ xylene cyanol) and denatured for $2 \mathrm{~min}$ at $92^{\circ} \mathrm{C} .2 .8 \mu \mathrm{l}$ of each sample were then loaded on a $5 \%$ acrylamide, $5 \%$ glycerol gel, and electrophoresed at room temperature in $0.6 \times \mathrm{TBE}$. Gels were dried and autoradiographed at room temperature for $6-12 \mathrm{~h}$.

\section{Direct Sequencing}

$E$ ach strand of DNA was amplified by asymmetric PCR with one of the two primers reduced 50 -fold in amount. The asymmetric PCR products were then filter-purified, concentrated, and $7 \mu \mathrm{l}$ were sequenced by the dideoxynucleotide chain-termination method using sequenase (U SB, U SA) and ${ }^{35} \mathrm{~S}$ dA TP.

\section{Results}

Mutations in RPE 65 were sought in 184 unrelated patients with various types of retinal dystrophies from whom informed consent had been obtained. For each patient the entire coding and flanking sequences ${ }^{12}$ were amplified by polymerase chain reaction (PCR) from genomic DNA and screened using single-strand conformation analysis (SSCA). Two major DNA sequence changes were noticed.

In one patient, direct sequencing of an aberrant migration pattern of the exon 9 revealed a 3-bp insertion at position 1047 (ins1047T G G) in one allele (not shown). The resulting protein should have an additional tryptophan at position 351, following tryptophan at position 350. A G to A substitution at position 1131 in exon 10 that does not change the encoded amino acid, was also found. ${ }^{12}$ The codon duplication ins1047TG G was not found in any of the other 183 unrelated patients. However, since it did not follow the segregation of the disease in the family, we conclude that it was not pathogenic.

In a second patient, an aberrant migration pattern was detected in exon 3 (patient $\mathrm{II}_{2}$ in Figure $1 \mathrm{c}$ ). D irect sequencing of this exon revealed a substitution of two consecutive nucleotides, changing $G$ to $T$ and $C$ to $T$ at cD NA positions 255 and 256, respectively (Figure 1a). This substitution resulted in a missense mutation, $\mathrm{H} 68 \mathrm{Y}$. Following this finding, the 13 other exons from this patient were sequenced who was found to carry a second alteration in exon 2 , substituting $T$ to $C$ at CD NA position 119, and resulting in a second missense mutation, L22P (Figure $1 b$ ). The segregation of the mutations was followed in the patient's family by SSCA using $\mathrm{H}$ ydrolink MDE gels for $\mathrm{H} 68 \mathrm{Y}$ and $5 \%$ acrylamide, $5 \%$ glycerol gels for $L 22 P$. This analysis revealed that $\mathrm{H} 68 \mathrm{Y}$ and $\mathrm{L} 22 \mathrm{P}$ were from maternal and paternal origins, respectively, confirming that the patient was a compound heterozygote (Figure 1c). The heterozygous carriers of either one of the two mutations were asymptomatic.

A mino acid substitutions in patient $\mathrm{II}_{2}$ are non conservative. Indeed, $\mathrm{H} 68 \mathrm{Y}$ results in the loss of one positive charge and the substitution of a leucine to a proline at codon 22 might disorganise the $\mathrm{C}$-terminal end of a hypothetical, amphipathic alpha helix. ${ }^{15} \mathrm{~B}$ oth $\mathrm{L} 22$ and $\mathrm{H} 68$ are conserved in human, ${ }^{16}$ bovine ${ }^{15}$ and rat [G enB ank accession number A F 035673] RPE 65, suggesting that they may be important for the protein function. In addition, these mutations have not been found in the other 183 unrelated patients nor in 50 normal individuals, strongly supporting that they are responsible for the disease in patient $\mathrm{II}_{2}$.

Patient $\mathrm{II}_{2}$ reported night blindness since early childhood and later on, in his second decade, complained of difficulties in reading, along with altered 
(a)

$\begin{array}{lll}\begin{array}{l}\text { Normal } \\ \text { allele }\end{array} & \begin{array}{l}\text { Mutant } \\ \text { protein }\end{array} & \begin{array}{l}\text { Normal } \\ \text { protein }\end{array}\end{array}$

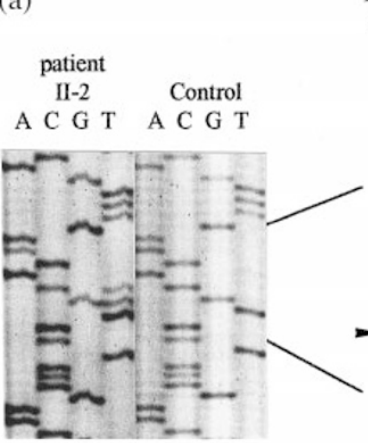

Mutant
allele

protein

protein

(b)

$\begin{array}{cc}\begin{array}{c}\text { Mutant } \\ \text { allele }\end{array} & \begin{array}{c}\text { Norma } \\ \text { allele }\end{array}\end{array}$

Mutant
protein

Normal

Patient 3', 3'

II-2 Control

A C G T A C G T

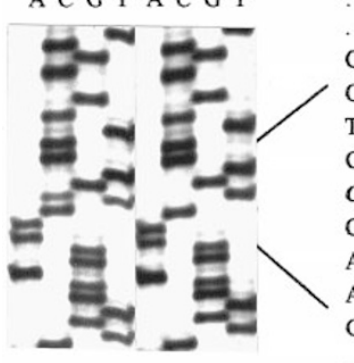

Ser 23

$\mathrm{T}$

G $\mid$ Pro (22)

C

\begin{tabular}{l|l} 
A & \\
A & Glu 21
\end{tabular}

$\mathrm{G}$

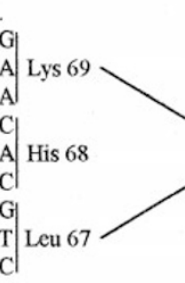

D

F

K

L

L

A

5, $\mathrm{NH} 2 \quad \mathrm{NH} 2$

Sense

$\begin{array}{ll}. & . \\ 5 & \\ \text { Sense } & 5\end{array}$

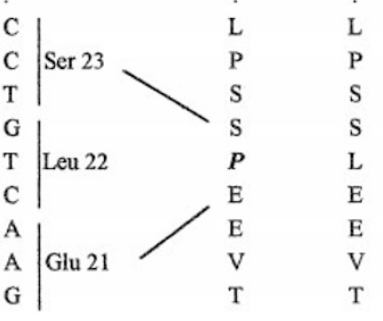

Sense

$\mathrm{NH} 2$

NH2

(c)

I

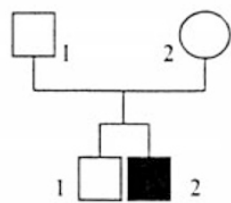

II

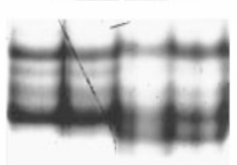

A

B

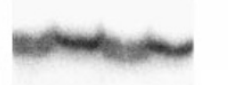

Figure 1 I dentification of two missense R PE 65 mutations in a single individual from one family. (a) sequences of R PE 65 exon 3 in patient $\mathrm{II}_{2}$ and an unaffected control. Two consecutive heterozygous substitutions at positions $255(\mathrm{G} \rightarrow \mathrm{T})$ and $256(\mathrm{C} \rightarrow \mathrm{T})$ are present in patient $\mathrm{II}_{2}$ (black arrow). $\mathrm{G} \rightarrow T$ does not change the encoded amino acid whereas $\mathrm{C} \rightarrow \mathrm{T}$ results in the substitution of histidine for tyrosine at codon 68. (b) sequences of R PE 65 exon 2 from the same individuals. A heterozygous T $\rightarrow$ C substitution at position 119 is present in patient $\mathrm{II}_{2}$ changing a leucine residue for a proline at codon 22. (c) inheritance pattern of R PE 65 mutations followed by SSCA analysis. Black symbol in the pedigree indicate the patient, white symbols unaffected family members. (A) SSCA of exon 3 displaying the shifted band associated with the heterozygote mutation $\mathrm{H} 68 \mathrm{Y}$ present in patient $\mathrm{II}_{2}$ and in his unaffected mother. (B) SSCA of exon 2 displaying a shifted band associated with the heterozygote L 22P mutation present in patient $\mathrm{II}_{2}$ and his unaffected father. 
colour discrimination. A t the time of the examination, aged 40 years, he was unable to find his way outside and exhibited marked peripheral field loss. Fundus examination revealed the triad, waxy pallor of optic discs, attenuated retinal vessels and bone-spicule pigment in midperipheral retina along with bilateral, extended dystrophy of the macular area. ER G responses for the scotopic system were undetectable $(<10 \mu \mathrm{V})$ and profoundly affected for the photopic system (flicker responses barely detectable). $\mathrm{H}$ is medical history and clinical findings were suggestive of a degenerative process involving both rods and cones.

\section{Discussion}

R esults from this study and recent findings ${ }^{12,13}$ demonstrate that mutations in a RPE-specific gene lead to retinal dystrophies (Figure 2). Shared phenotypic features in patients with RPE 65 mutations are early onset of the disease along with rapid progression of the degenerative process. The most severe clinical picture was described in two patients ${ }^{12}$ as Leber's congenital amaurosis (LCA ), a retinal dystrophy characterised by severe visual impairment at birth with extinguished ERG responses. ${ }^{17}$ In contrast, patient $\mathrm{II}_{2}$ described in this study exhibited a milder phenotype in childhood and a slower progression of the disease. LCA patients were compound heterozygotes for nonsense mutations implying that the truncated RPE 65 products were either absent or nonfunctional. In the case of patient $\mathrm{II}_{2}$ described in this study, the two missense mutations probably result in misfolded or functionally impaired but full-length RPE 65 products. O ne can speculate that the level of impairment of the RPE 65 protein might control the rate at which the photoreceptors degen- erate. Following this hypothesis, the absence of RPE 65 products would cause a massive, early degeneration of photoreceptors while substitution of amino acids would lead to a slower pace of degeneration. In fact, brief description of phenotypes with RPE 65 mutations reported by $\mathrm{Gu}$ et al ${ }^{13}$ suggests that premature stop codon or frameshift lead to more severe phenotype than inactivated splice site or amino acid substitutions.

Understanding of the pathogenesis of retinal dystrophy in the case of RPE 65 mutations will require a knowledge of the function of the protein itself. B ecause of its strict specificity for the RPE and of its conservation in vertebrates, RPE 65 is a good candidate for one of the few specialized functions of the RPE. A mong these, the metabolic pathway that processes the alltrans-retinol to 11-cis-retinoids and that takes place in the R PE represents a key to the proper functioning of the photoreceptors. ${ }^{9}$ I mportant steps of this metabolism involve a lecithin:retinol acyltransferase that esterifies dietary-derived all-trans-retinol (vitamin A), an isomerase that directly converts the retinyl ester to 11-cisretinol and an 11-cis-retinol dehydrogenase that oxidises 11 -cis-retinol to 11 -cis-retinal ${ }^{18}$ which eventually associates with opsins to form photopigments. The isomerase and the 11-cis-retinol dehydrogenase are both RPE-specific microsomal enzymes, ${ }^{19,20}$ as is R PE 65. In addition, R PE 65 appears to form a protein complex with the 11-cis-dehydrogenase and with at least two unidentified products of 50 and $52 \mathrm{kDa}{ }^{21}$ These observations and the recent demonstration that addition of anti-RPE 65 antibodies to RPE extracts causes a decrease in the de novo generation of 11-cisretinoids ${ }^{11}$ suggest that RPE 65 is an enzyme involved in the 11-cis-retinoid metabolism. Therefore, a defect in

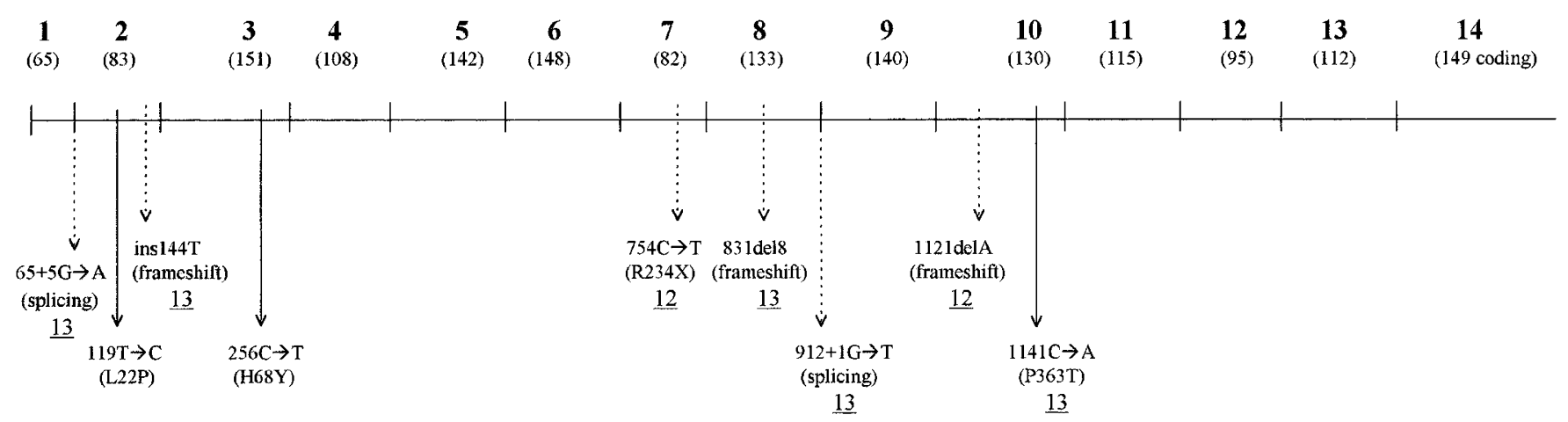

Figure 2 M utations in R PE 65. Schema depicting the 14 exons of R PE 65. Number of each exon is indicated as well as its size in bp in brackets. R eported R PE 65 mutations are described; underlined numbers refer to references in this paper; solid line arrows indicate amino acid substitutions, dashed line arrows are for translation terminating mutations. 
the R PE 65 function could lead to decreased or abnormal rod and cone photopigments resulting in degeneration of photoreceptors. The medical history of patient $\mathrm{II}_{2}$ described in this study as well as clinical findings from recent reports ${ }^{12,13}$ indeed suggest that both rods and cones are involved in the degenerative process. A nimal models are needed to examine these hypotheses and to give further insight into the interactions between photoreceptor and RPE in retinol metabolism.

\section{Acknowledgements}

J-M G and CB are supported by SOS R étinite, M ontpellier, France. R esearch was sponsored in part by SOS Rétinite, IRRP and R etina France, and by the CHU de M ontpellier, France. We gratefully thank Jean-Louis Pasquier for artwork.

\section{References}

1 Boughman JA, Conneally PM, Nance WE: Population genetic studies of retinitis pigmentosa. A $\mathrm{m} J \mathrm{H}$ um $\mathrm{G}$ enet 1980; 32: 223-234.

2 Pagon R A : R etinitis pigmentosa. Surv O phthalmol 1988; 33: 137-177.

3 H eckenlively J R: R P cone-rod degeneration. Trans A m O phthalmol Soc 1987; 85: 438-470.

4 Kaplan J, Bonneau D, Frézal J, M unnich A, D ufier J -L: Clinical and genetic heterogeneity in retinitis pigmentosa. H um G enet 1990; 85: 635-642.

5 D ryja TP, Li T: M olecular genetics of retinitis pigmentosa. H um M ol G enet 1995; 4: 1739-1743.

6 Sullivan LS, Daiger SP: Inherited retinal degeneration: exceptional genetic and clinical heterogeneity. M ol Med Today 1996; 2: 380-386.

7 Young RW, Bok D: Participation of the retinal pigment epithelium in the rod outer segment renewal process. J Cell Biol 1969; 42: 392-403.

8 Bok D, Hall MO: The role of the pigment epithelium in the etiology of inherited retinal dystrophy in the rat. J Cell Biol 1971; 49: 664-682.
9 Wald G: The molecular basis of visual excitation. Nature 1968; 219: 800-807.

$10 \mathrm{H}$ amel $\mathrm{CP}$, Tsilou $\mathrm{E}, \mathrm{H}$ arris $\mathrm{E}$ et al: A developmentally regulated microsomal protein specific for the pigment epithelium of the vertebrate retina. J Neurosci Res 1993; 34: 414-425.

11 Crouch R K, G oletz P, Y u S, R edmond TM : A possible role for $R P E 65$ in retinoid processing. Invest 0 phthalmol Vis Sci 1997; 38: S304.

12 Marlhens $F, B$ areil $C$, G riffoin J - $M$ et al: Mutations in RPE 65 cause Leber's congenital amaurosis. $\mathrm{N}$ at $\mathrm{G}$ enet 1997; 17: 139-141.

13 Gu S-M, Thompson DA, Srisailapathy Srikumari CR et al: Mutations in RPE65 cause autosomal recessive childhood-onset severe retinal dystrophy. Nat G enet 1997; 17: 194- 197.

14 Tuffery S, Moine P, Demaille J, Claustres $M$ : B ase substitutions in the human dystrophin gene: detection by using single-strand conformation polymorphisms (SSCP) technique. H um M ut 1993; 2: 368-374.

$15 \mathrm{H}$ amel CP, Tsilou E, Pfeffer BA, Hooks JJ, Detrick B, Redmond TM: Molecular cloning and expression of R PE 65, a novel retinal pigment epithelium-specific microsomal protein that is post-transcriptionally regulated in vitro. J Biol Chem 1993; 268: 15751-15757.

16 Nicoletti A, Wong DJ, Kawase $K$ et al: Molecular characterization of the human gene encoding an abundant $61 \mathrm{kD}$ a protein specific to the retinal pigment epithelium. H um M olec G enet 1995; 4: 641-649.

17 Leber T: Über retinitis pigmentosa und angeborene A maurose. Graefes Arch K lin Exp O phthalmol 1869; 15: 13-20.

$18 \mathrm{R}$ ando $\mathrm{R} \mathrm{R}$ : M embrane phospholipids as an energy source in the operation of the visual cycle. Biochemistry 1991; $\mathbf{3}$ : 595-602.

19 Hubbard R : R etinene isomerase. J Gen Physiol 1956; 39: 935-962.

20 Lion F, R otmans JP, Daemen FJM, Bonting SL: B iochemical aspects of the visual process. XVII Stereospecificity of ocular retinol dehydrogenase and the visual cycle. Biochim Biophys A cta 1975; 384: 283-292.

21 Simon A, Hellman U, Wernstedt C, E riksson U: The retinal pigment epithelial-specific 11-cis retinol dehydrogenase belongs to the family of short chain alcohol dehydrogenases. J B iol Chem 1995; 270: 1107-1112. 